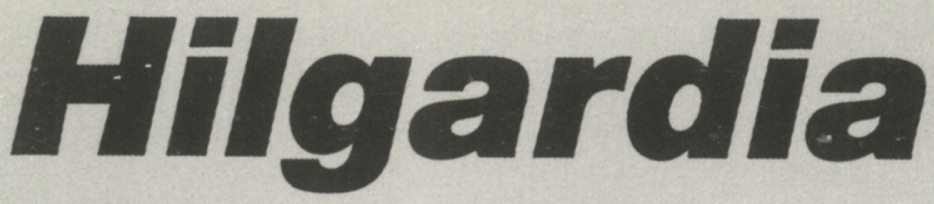

A. JOURNAL OF AGRICULTURAL SCIENCE PUBLISHED BY THE CALIFORNIA AGRICULTURAL EXPERIMENT STATION

Volume 55 • Number 8 - October 1987

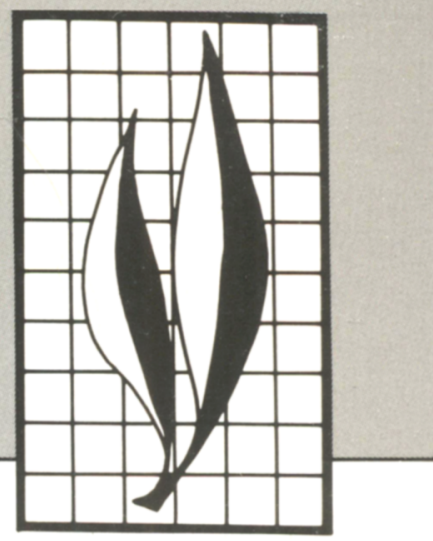

\title{
Tree Height and Diameter Growth Models for Northern California Conifers
}

Lee C. Wensel, Walter J. Meerschaert, and Greg S. Biging 


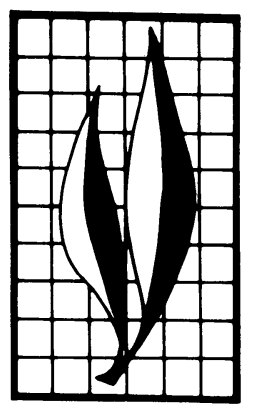

\begin{abstract}
This paper presents growth models for predicting the components of height and diameter growth for six conifer species in northern California. Sample data came from the lands of the industry members of the Northern California Forest Yield Cooperative, and the coefficients were developed for use in CACTOS, the California Conifer Timber Output Simulator. The basic field data required for predictions are 50year (at breast height) site indexes for each species in the stand as well as the following items for each tree: species, diameter at breast height, total height, height to the crown base, and number of trees per acre. The models express growth as a product of potential and competition components. For height growth the potential is based upon 50-year (breast height) site index curves while for diameter growth, potential coefficients come from an iterative procedure using "free to grow" trees as a starting point. The competition components rely primarily upon the relative position of the crown, expressed as the crown closure at 66 percent of the tree's height. Data from stem analysis were used to fit the height growth coefficients, but both the stem analysis and increment core data were used to fit and test the diameter growth coefficients.
\end{abstract}

\title{
THE AUTHORS:
}

Lee C. Wensel is Professor, Department of Forestry and Resource Management, University of California, Berkeley.

Walter J. Meerschaert is Assistant Specialist, Department of Forestry and Resource Management, University of California, Berkeley.

Greg S. Biging is Associate Professor, Department of Forestry and Resource Management, University of California, Berkeley. 


\section{Tree Height and Diameter Growth Models for Northern California Conifers ${ }^{1}$}

\section{INTRODUCTION}

ESTIMATES OF FOREST growth are of vital importance to the forestland manager. Growth rates determine the rates of return on investment and, hence, of the forestry operation. Thus, to develop optimum forest regulation plans, estimates of growth rates for each alternative management practice must be available.

The objective here is to present estimates of tree growth rates for use with forest stands in the mixed-conifer region of northern California. An individual tree distanceindependent modelling approach is taken to provide the flexibility and detail required to enable the model to be used with forest inventory data. By separating the estimated growth potential and competition components, the user is able to modify the competition component (through partial harvests) to predict the effects of alternative management prescriptions for established forest stands. The predicted yields can then be used in developing optimized management plans for the forest. The equations developed here can be used to predict the growth of trees in even-aged single-species or mixedspecies stands, multiple-aged stands (individual ages usually unknown), and trees that are now or have been previously suppressed. However, the majority of the data used for model development were from mixed species, multiple-aged stands, and little testing was done with single-species plantations. Tree diameters ranged from 6 to 36 inches.

The growth estimators described here are incorporated in CACTOS, the California Conifer Timber Output Simulator (Wensel, Daugherty, and Meerschaert 1986). They use the data and research results of the Northern California Forest Yield Research Cooperative as described below.

\section{DATA}

The growth coefficients presented result from analyzing data collected in cooperation with 12 forest industry contributors of the Northern California Forest Yield Cooperative. They consist of tree measurements from two sources, permanent plots and stem analysis plots. These data come from samples taken throughout northern California and are selected to represent the growth of six conifer species (see table 1) in young-growth forest stands within the ownership of the industry cooperators.

\section{Stem Analysis Plots}

The stem analysis data described by Biging $(1984,1985)$ consist of measurements on both felled and standing trees. A total of 39 cluster plots were chosen for measurement by the cooperators; 31 clusters of three one-fifth acre (0.08 ha) plots and 8 clusters of two one-tenth acre ( $0.04 \mathrm{ha})$ plots. On each plot, approximately 12 trees were selected for falling, including four to six dominants to represent the one or two

${ }^{1}$ Accepted for publication July 23, 1987. 
TABLE 1. DEFINITION OF SPECIES CODES USED

\begin{tabular}{ll}
\hline \hline Code & Definition \\
\hline PP & Ponderosa pine \\
& Pinus ponderosa (Laws.) \\
SP & Sugar pine \\
& Pinus lambertiana (Dougl.) \\
DF & Douglas-fir \\
& Pseudotsuga menziesii (Mirb.) Franco \\
WF & White fir \\
& Abies concolor (Gord. and Glend.) Lindl. \\
RF & Red fir \\
& Abies magnifica (A. Murr.) \\
IC & Incense cedar \\
& Libocedrus decurrens (Torr.) \\
\hline
\end{tabular}

most prevalent species in the stand, and up to seven trees randomly selected to represent the range of diameter classes present. The distribution of these plots in northern California is shown on figure 1. The clusters ranged in stocking from 70 to 305 square feet of basal area per acre (16 to 70 square meters per hectare). Most of the clusters (22) were in the mixed-conifer timber type, with no single species making up 80 percent or more of the basal area. The other clusters were distributed as follows: 3 in the ponderosa pine type, 4 in the Douglas-fir type, and 10 in the true fir type.

For the felled trees, diameter growth was obtained by computer analysis of digitized tree cross sections (Biging and Wensel 1984), and height growth was estimated by interpolation on 5-, 10-, and 15-year tip cuts. For the trees that were not felled on a subplot, diameter growth was obtained using increment cores. No height growth measurements were taken from the nonfelled trees.

The individual trees were backdated by subtracting the previous 5-year diameter and height growth from current measurements. The backdating process allowed us to model growth rates as a function of the tree size at the beginning of the previous growth cycle. Stand density and mortality rates were recomputed from the revised tree lists. However, for backdating, the live crown ratio was assumed to remain the same for the 5-year growth cycle.

\section{Permanent Plots}

Parallel to the stem analysis work, data were collected by cooperators on a total of 710 permanent plots geographically located over a slightly wider area than the stem analysis plots, representing a wider range of stand conditions (see fig. 1). Increments from two breast-height borings (at 90 degrees from one another) were used to estimate diameter growth. Initially, 50 plots were installed by each cooperator, distributed over the various young-growth timber types, site index classes, and stocking levels present. This number was subsequently increased by some cooperators to represent the wider range of conditions present.

Figure 2 shows the number of permanent plots by region. Four regions were recognized: (1) the northern Sierra Nevada, (2) the southern Cascades, (3) the Shasta- 

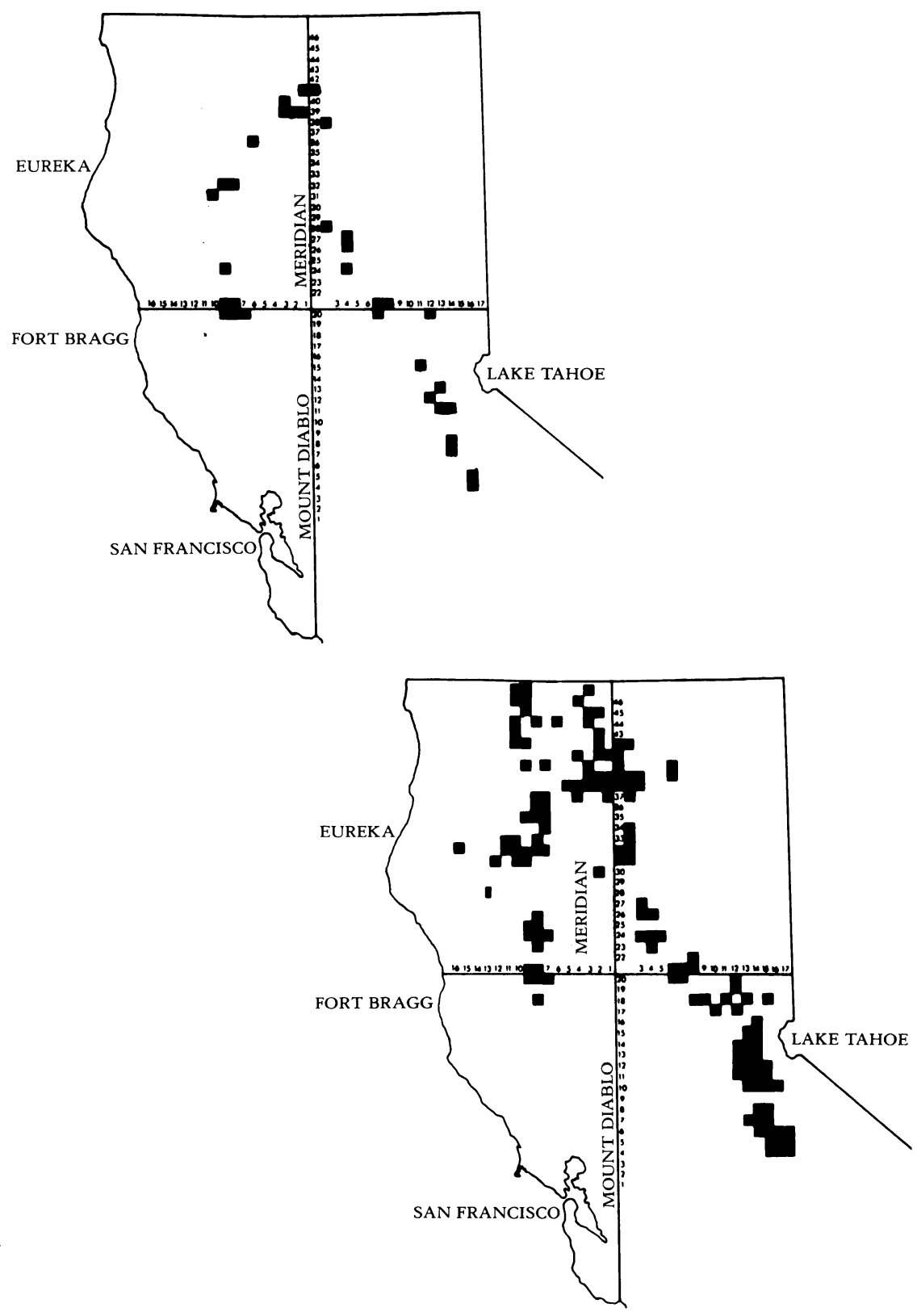

Fig. 1. Distribution of sample data for growth models; $(a)$ stem analysis plots and $(b)$ permanent plots. Numbered lines show township and range coordinates of plot locations. 


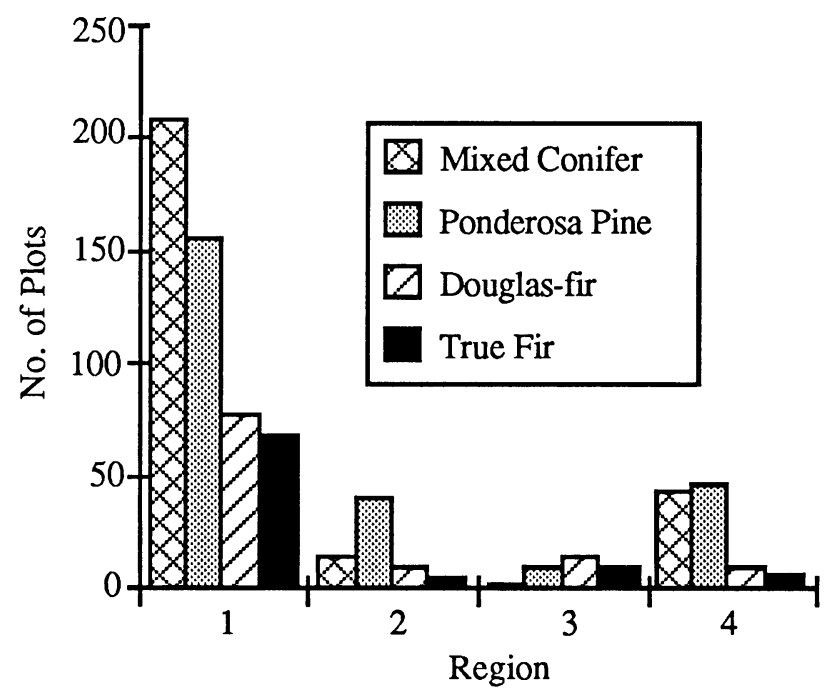

Fig. 2. Number of permanent plots by region for each timber type.

Trinity area, and (4) the east side of the Mendocino range. Region 1 was the most heavily sampled, with the mixed-conifer type predominating. (Ponderosa pine, Douglasfir, and true fir types contain at least 80 percent of the stand basal area in the singlespecies plots while the mixed-conifer type has at least 80 percent conifer but no one species makes up more than 80 percent of the stand basal area.) The numbers of plots by stocking levels are illustrated in figure 3. Note that the first four of the stocking classes are represented in all of the timber types and the most dense class is not well represented in either the ponderosa pine or Douglas-fir types. However, these two species did occur in denser stands in the mixed conifer type.

A research plan and measurement standards were established so that data obtained from these permanent plots could be combined into a compatible computerized database for analysis. For analysis, each tree was assigned to one of two subsets at random. One subset was used to estimate the diameter growth model coefficients and the other provided an independent check on the estimated coefficients. This procedure is discussed further in the "Results" sections.

\section{GROWTH MODELS}

Actual tree diameter and height growth are modelled as the product of the tree's potential growth and a measure of competition that restricts that tree's ability to reach its potential (Baule, 1917). That is,

$$
\text { growth }=(\text { potential growth }) \times(\text { competition })
$$

where potential growth is based on a theoretical estimate of the growth rate of a dominant tree of that size and the competition component is based upon some measure of stand density and relative tree size. Since one of the objectives is to predict the 


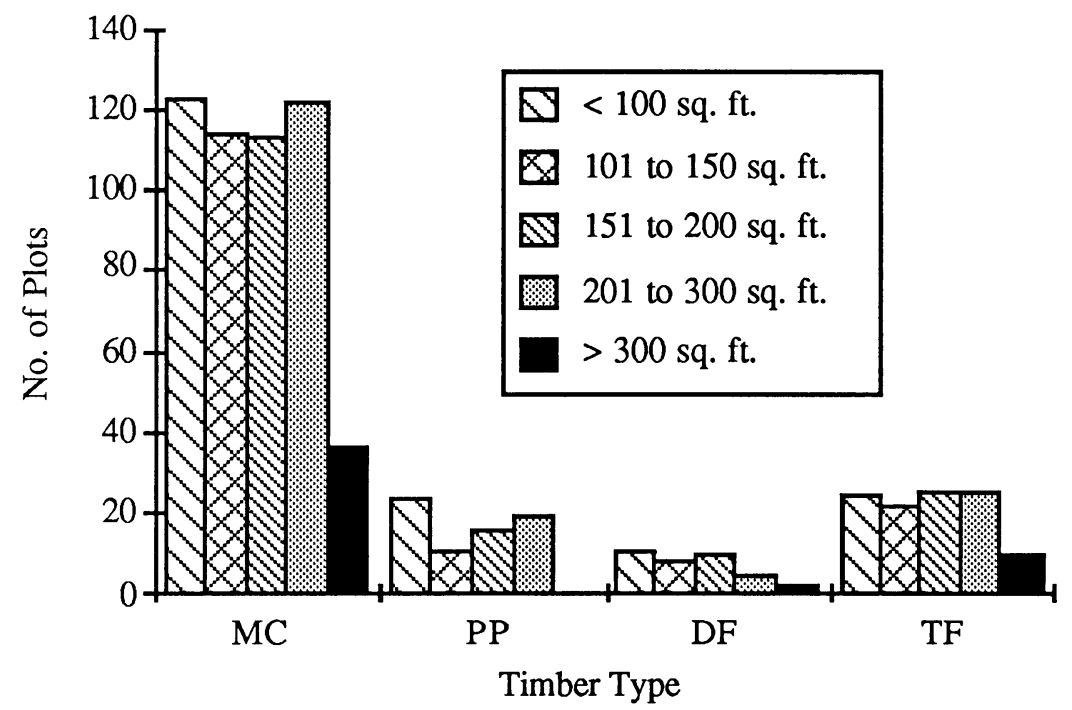

Fig. 3. Number of permanent plots by timber type and stocking level.

growth rates of residual trees after thinning or natural mortality, the potential growth rate is adjusted by a factor reflecting the ability of the tree to take advantage of the growing space made available. Seidel (1980), Helms and Standiford (1985), Oliver (1986), Ferguson and Adams (1980), and others have found that the amount of photosynthetic area is a factor in determining the growth rates of released trees. Trees with low levels of photosynthetic area, as indicated by low live crown ratios, are not able to respond to release as quickly as trees with larger live crown ratios. Thus an adjustment was made on the potential growth based upon the tree's live crown ratio. This adjustment is applied separately below for the height and diameter components of growth.

While there are some differences in previously published formulations of the potential growth components, the major differences in these models are in the formulation of the component for competition. Monserud (1975) expressed the competition component used in the northern hardwood simulation model FOREST (Ek and Monserud, 1974) as a product of "growth multipliers," the principal one being a distancedependent competition index. For the North Central region growth simulation model STEMS, Leary and Holdaway (1979); Hahn and Leary (1979); and Belcher, Holdaway, and Brand (1982) used asymptotic functions of tree size, relative tree size, current stocking, and the maximum stocking level expected on the site.

In CRYPTOS, a growth simulation routine for California's redwood region, Krumland and Wensel (1981, 1982); and Krumland (1982) expressed competition as an asymptotic function of crown size and crown competition at two-thirds of each tree's height. While these variables were tested in the present study, the CRYPTOS models failed to produce unbiased estimates of growth when fitted to the data used here. Thus, a reformulation of the diameter and height growth components of the model was warranted. 
The component approach, built largely on theoretical models with empirically derived coefficients, contrasts to the empirical approach used in models such as PROGNOSIS (Stage 1973; and Wykoff, Crookston, and Stage 1982), a model widely used in the West by the U.S. Forest Service. The empirical models are developed to predict future growth based upon correlation observed between the independent and dependent variables. While theoretical models depend upon data for their scale, empirical models may depend upon the data for both their form and scale. In practice, however, most modelling efforts have components of each type-theoretical and empirical.

Martin and Ek (1984), using red pine stands in Wisconsin, compared a semiempirical model similar to the component model used here to a decidedly empirical model similar to that used in the PROGNOSIS model (Stage 1973, 1975). Using test data, Martin and Ek's study showed bias in all of the estimates. However, it is interesting to note that the empirical model appeared to be more accurate for managed stands but was highly biased for unmanaged stands, where their semi-empirical model performs better. These results were based upon 17 one-acre sample plots.

In the discussion that follows, potential and competition components are developed for both height and diameter at breast height (DBH) growth. The approach used is similar to that used for red pine plantations by Martin and Ek (1984) and for redwood and Douglas-fir forests by Krumland and Wensel (1981); and Krumland (1982).

\section{Potential Height Growth}

The potential height growth is derived from the site index curves given by Biging and Wensel (1985) and Biging (1985):

$$
\mathrm{H}=4.5+\mathrm{b}_{0} \mathrm{~S}^{\mathrm{b}_{1}}\left[1-\exp \left(-\mathrm{b}_{2} \mathrm{~A}\right)\right]^{\mathrm{b} 3}
$$

where $\mathrm{H}$ is the total tree height, $\mathrm{A}$ is breast-height age, and $\mathrm{S}$ is site index. The coefficients, derived using a varying-parameter model, are: $b_{0}=2.93243, b_{1}=0.89$, $b_{2}=0.024$, and $b_{3}=1.8184$. Site index is specified separately for each species present in the stand.

The expression for height growth is based on the proposition that the potential change in height follows the site index curve from the tree's current height to what it would be 5 years later. Thus, using an inverted form of equation [1], a nominal tree age is computed for a tree of height $\mathrm{H}$ on site index S. Monserud (1975) referred to this inverse of the height-age equation as the tree's physiological age. Adding 5 years to this age and substituting into equation [1] and subtracting current height, yields the expression for the potential height growth for the 5-year cycle. This process is illustrated in figure 4 (also see Monserud 1975, p. 55). Explicitly, denoting the function in equation [1] as $\mathrm{f}(\mathrm{A})$, the physiological age in equation [1] becomes $\mathrm{f}^{-1}(\mathrm{H})$, and the estimated potential change in height becomes

or

$$
\begin{aligned}
& P_{H}=f(\text { physiological age }+5)-\text { current height } \\
& P_{H}=f\left(f^{-1}(H)+5\right)-H
\end{aligned}
$$

where, by inversion of equation [1],

$$
f^{-1}(H)=-\left(1 / b_{2}\right) \log \left\{1-\left[H_{b} /\left(b_{0} S^{b_{1}}\right)\right]^{1 / b_{3}}\right\}
$$

and

$$
\log =\text { natural logarithm }
$$

$$
\mathrm{H}_{\mathrm{b}}=\mathrm{H}-4.5
$$




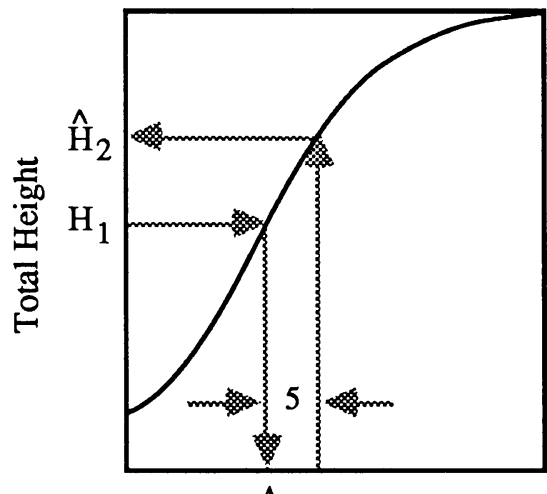

A

Breast Height Age
Fig. 4. Illustration of height growth potential determination.

Note that site index reflects the average height of dominant and codominant trees and, therefore, the potential height growth could be somewhat higher than that obtained by using equation [2]. As a result, while fitting the competition coefficients (below), a site index adjustment $(\partial)$ was estimated for each species such that the potential height growth is computed using site index $S^{\prime}$; thus

$$
\mathrm{S}^{\prime}=\mathrm{S}+\partial
$$

is used in place of $S$ in equation [2].

\section{Crown adjustment}

The estimate of the potential tree height growth is further adjusted based upon the tree's crown ratio under the premise that a tree cannot grow at the potential of a given site unless it has a sufficiently large crown. This gives the crown-adjusted height growth potential, $\mathrm{P}_{\mathrm{H}^{\prime}}$, as

$$
\mathrm{P}_{\mathrm{H}^{\prime}}=\mathrm{P}_{\mathrm{H}} \mathrm{d}_{1} /\left[1+\exp \left(4-\mathrm{d}_{2} \mathrm{LCR}\right)\right]
$$

and the crown-adjusted $\mathrm{DBH}^{2}$ growth, $\mathrm{P}_{\mathrm{D}^{\prime}}$, as

$$
\mathrm{P}_{\mathrm{D}^{\prime}}=\mathrm{P}_{\mathrm{D}} /\left[1+\exp \left(4-\mathrm{d}_{2} \mathrm{LCR}\right)\right]
$$

where LCR is the live crown ratio, $d_{1}=1$ (except for red fir and incense cedar height growth) and $d_{2}$ is a constant shown to be about 20 for all species. Thus, the live crown ratio is used in [4] with current height to represent the current photosynthetic potential of the tree. The effect of this adjustment is shown in figure 5. For a tree with live crown ratio greater than 0.5 , the adjustment is 1.0 and has no effect on the values of the potential height growth. However, for live crown ratio less than 0.5 there is a significant reduction in the tree's potential height growth. This relationship appears to be similar in form and extent for all species tested. 


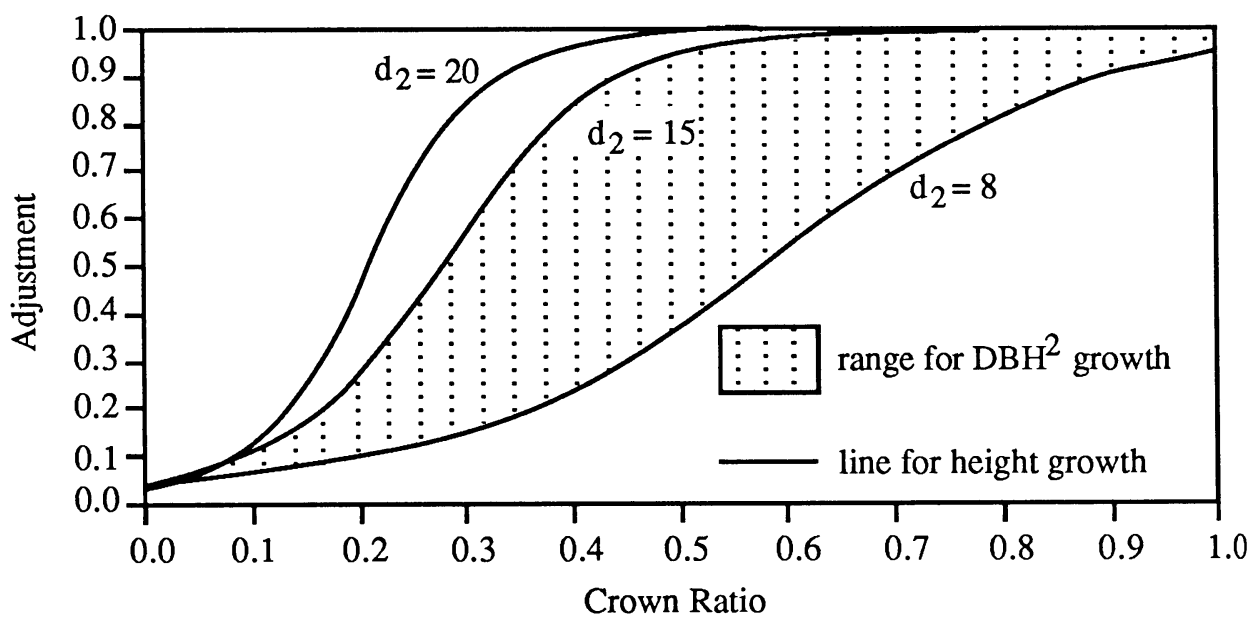

Fig. 5. Illustration of reduction of growth potential due to live crown ratio $\left(\mathrm{d}_{1}=1\right)$.

\section{Potential Diameter Growth}

Diameter growth curves analogous to site index curves do not exist since diameter growth is more sensitive to competition than height growth. Also, there are no generally accepted upper asymptotes for $\mathrm{DBH}$ growth. Therefore the following procedure was developed for estimating the diameter growth potential component.

In a manner similar to that for potential height growth, potential $\mathrm{DBH}^{2}$ growth is viewed conceptually as a function of site index and age as:

$$
D^{2}=b_{0} S^{b_{1}}\left[1-\exp \left(-5 b_{2} A\right)\right]^{b_{3}}
$$

where $\mathrm{D}$ is the tree $\mathrm{DBH}, \mathrm{S}$ is the species-specific site index, $\mathrm{A}$ is the breast height age of the tree and $b_{0}, b_{1}, b_{2}$, and $b_{3}$ are coefficients. Using the relationship given by equation [5], the potential diameter-squared growth corresponding to equation [2] for height growth is

$$
P_{D}=\left[c_{0} S^{c 1}+c_{2} D^{2 c_{3}}\right]^{1 / c_{3}}-D^{2}
$$

where

$$
\begin{aligned}
& c_{0}=\left[1-\exp \left(-5 b_{2}\right)\right] b_{0}{ }^{\left(1 / b_{3}\right)} \\
& c_{1}=b_{1} / b_{3} \\
& c_{2}=\exp \left(-5 b_{2}\right) \\
& c_{3}=1 / b_{3}
\end{aligned}
$$

The coefficients in equation [6] were fitted directly by nonlinear least squares.

As in the case of height growth potential, a crown adjustment was made on the potential diameter growth to reflect the reduction in the potential growth due to insufficient crown. The form of the adjustment is the same as that shown in equation [4] for height growth except that the impact is greater, corresponding to the lines for $\mathrm{d}_{2}$ from 8 to 15 in figure 5 . Values of $d_{2}$ are given for each of the six species in the "RESULTS" section. 


\section{Measures of Competition}

Distance-independent measures of competition have been compared with measures based upon the tree's location within the stand (distance-dependent measures) by Opie (1968); Martin and Ek (1984); and Daniels, Burkhart, and Clason (1987). In general, these studies showed that distance-independent measures perform on a level with more complicated distance-dependent measures, making the expense of recording tree position unnecessary. Further, while tree spacing is theoretically important in determining tree growth rates, empirical studies show that relative location within the stand can be reflected using other measures. Working in hardwood stands, Lorimer (1983) found distance-dependent measures of competition to perform better than basal area, particularly when competitors were of equal or higher crown class. Our measure of competition is designed to reflect the relative vertical position of the tree in the stand. Hence it reflects the location of the tree only on a statistical basis.

The form of the height growth competition $\left(C_{H}\right)$ factor is as follows:

$$
\mathrm{C}_{\mathrm{H}}=\exp \left(\mathrm{d}_{3} \mathrm{CC}_{66} \mathrm{~d}_{4} \mathrm{PBA}^{\mathrm{d}_{5}}\right)
$$

where $\mathrm{CC}_{66}$ is the crown area at 66 percent of the subject tree's height, PBA is the proportion of the basal area of that species in the stand, and the coefficients $d_{3}, d_{4}$, and $d_{5}$ are estimated for each species using nonlinear regression. Crown closure, $\mathrm{CC}_{66}$, is used to reflect the density of the plot as it affects the photosynthetic portion of the crown (Krumland and Wensel 1981; and Krumland 1982), and estimates are obtained as a function of $\mathrm{DBH}$, total height, and live crown ratio as illustrated in the next section. Alternative formulations of this model were fitted using the sum of basal area for trees larger than the subject tree (BAL) in place of $\mathrm{CC}_{66}$. This measure is used to good advantage by Monserud (1975); and Wykoff, Crookston, and Stage (1982). BAL is easily computed and does not depend on the crown models. While BAL produced a reasonable statistical fit here for most species, it does not reflect the vertical profile of the stand.

The competition component for diameter growth follows the same logic as the height competition component. The variable PBA does not cast the same influence on diameter growth as it does on height growth, therefore it is left out of the diameter component (i.e., $d_{5}=0$ ). The final form of the competition component is given as:

$$
C_{D}=\left[\exp \left(d_{3} C C_{66} d_{4}\right)\right]
$$

Failures, if any, of the equations [2] and [6] to represent the potential growth will likely be compensated for by the competition components, equations [7] and [8]. While this improves the accuracy of the predictions for the current data set, any inability to represent the separate components presents a problem in applying the results of the simulation to real forest conditions. Simulated management activities will change the competition component, but not the potential components or the crown adjustment. Thus failures to estimate these individual components correctly will lead to incorrect estimates of the effects of management activities.

For simply predicting change in $\mathrm{DBH}$ or height, the product of the potential and competition equations may appear over-parameterized. If it was not necessary to separate the two components for use in the simulator, a simplified model with fewer parameters might be possible. However, the number of coefficients used here is similar to the number used in the empirical model by Stage (1975); Wykoff, Crookston, and 
Stage (1982); and Wykoff (1985) and in both the empirical and semi-empirical models by Martin and Ek (1984).

\section{Crown closure at 66 percent of tree's height}

Computation of crown closure, $\mathrm{CC}_{66}$, is illustrated in figure 6 where the values of $\mathrm{C}_{66}$ are illustrated for the trees shaded. In figure $6(a)$, the center tree is shorter than the others, giving it a higher value of $\mathrm{C}_{66}$ than for the left tree in figure $6(b)$ or for the right tree in figure $6(c)$. Note that, as measured by $\mathrm{CC}_{66}$, the center tree contributes nothing to the crown competition for the tallest tree shown in figure $6(c)$.

The crown estimates used here were developed from initial crown models by Van Deusen and Biging (1984); and Biging and Wensel (1987). Using the same felled tree data used in this study, Biging and Wensel (1987) estimated the crown volume by the expression

$$
\mathrm{CV}=\mathrm{a} \mathrm{D}^{\mathrm{b}} \mathrm{H}^{\mathrm{c}} \mathrm{LCR}^{\mathrm{d}}
$$

where as before, $\mathrm{D}$ is tree $\mathrm{DBH}, \mathrm{h}$ is tree total height, $\mathrm{LCR}$ is tree live crown ratio, and $\mathrm{a}, \mathrm{b}, \mathrm{c}$, and $\mathrm{d}$ are coefficients given by species in table 2 . They also estimated the crown cross-sectional area at height $\mathrm{h}, \mathrm{CA}(\mathrm{h})$, as

and

$$
\mathrm{CA}(\mathrm{h})=\mathrm{k} \mathrm{CV}(\mathrm{H}-\mathrm{HCB})^{-1} \quad 0<\mathrm{h} \leq \mathrm{HCB}
$$

$$
\mathrm{CA}(\mathrm{h})=\mathrm{k} \mathrm{CV}(\mathrm{H}-\mathrm{h})^{\mathrm{k}-1}(\mathrm{H}-\mathrm{HCB})^{-\mathrm{k}} \quad \mathrm{HCB}<\mathrm{h} \leq \mathrm{H}
$$

where HCB is the height to the crown base, $\mathrm{CV}$ (crown volume) is estimated using equation [9], and the values for $\mathrm{k}$ are given by species in table 2 . These models, illustrated in figure 7, define the projection from the base of the crown to ground level (equation [10]), as well as the crown taper from the base of the crown to the tip (equation [11]).

Using equations [10] and [11], $\mathrm{CC}_{66}$ is computed for each tree in the stand as follows, for tree $\mathrm{i}, \mathrm{i}=1,2,3 \ldots, \mathrm{n}$ :

$$
\mathrm{CC}_{66_{i}}=\Sigma_{\mathrm{j}} \mathrm{CA}_{\mathrm{j}}\left(\mathrm{h}_{\mathrm{i}}\right) \times \mathrm{TPA}_{\mathrm{j}} / 43,560
$$

where $h_{i}=0.66 \mathrm{H}_{i}, \mathrm{H}_{\mathrm{i}}$ is the total height of tree $\mathrm{i}, \mathrm{TPA}_{\mathrm{j}}$ is the number of trees per acre represented by tree $\mathrm{j}$, and $\Sigma_{\mathrm{j}}$ is the sum for all trees on the plot $(\mathrm{j}=1,2, \ldots, \mathrm{n})$. Dividing by the number of square feet in an acre, 43,560, converts the absolute area to relative area commonly used for expressing crown closure.

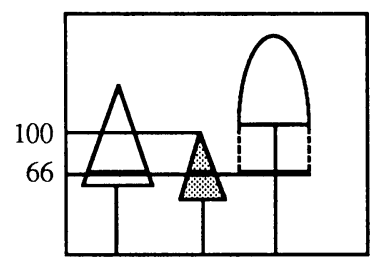

(a)

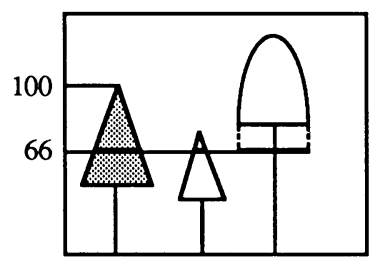

(b)

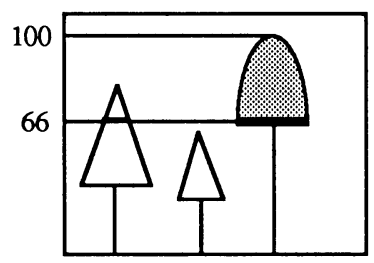

(c)

Fig. 6. Crown cross-sectional area at 66 percent of tree's height. $\left(\mathrm{CC}_{66}\right.$ shown by bold line for shaded tree.) 
TABLE 2. COEFFICIENTS FOR CROWN MODELS EQUATIONS [9], [10], and [11].*

\begin{tabular}{cccrrrr}
\hline Coef. & PP & SP & DF & WF & RF & IC \\
\hline a & 5.287 & 5.287 & 16.236 & 11.984 & 9.572 & 8.909 \\
b & 1.314 & 1.314 & 0.976 & 0.952 & 0.952 & 1.124 \\
c & 1.000 & 1.000 & 1.000 & 1.000 & 1.000 & 1.000 \\
d & 1.922 & 1.922 & 1.463 & 1.564 & 1.564 & 1.727 \\
k & 1.785 & 1.785 & 1.805 & 2.004 & 2.040 & 1.702 \\
\hline
\end{tabular}

*Fit statistics and complete information can be found in Biging and Wensel (1987).

\section{RESULTS}

The stem analysis data were used to estimate the height growth coefficients and to test the $\mathrm{DBH}^{2}$ coefficients. As shown above, the broad base of the permanent plot database made it well suited for estimating the $\mathrm{DBH}^{2}$ growth coefficients, even though these data could not be used to estimate the height growth coefficients.

\section{Height Growth Coefficients}

Table 3 shows the estimated coefficients for the height growth model given in equations [3], [4], and [7]. Although there are five coefficients in the complete height growth model, table 3 shows that no more than four were coefficients estimated for any

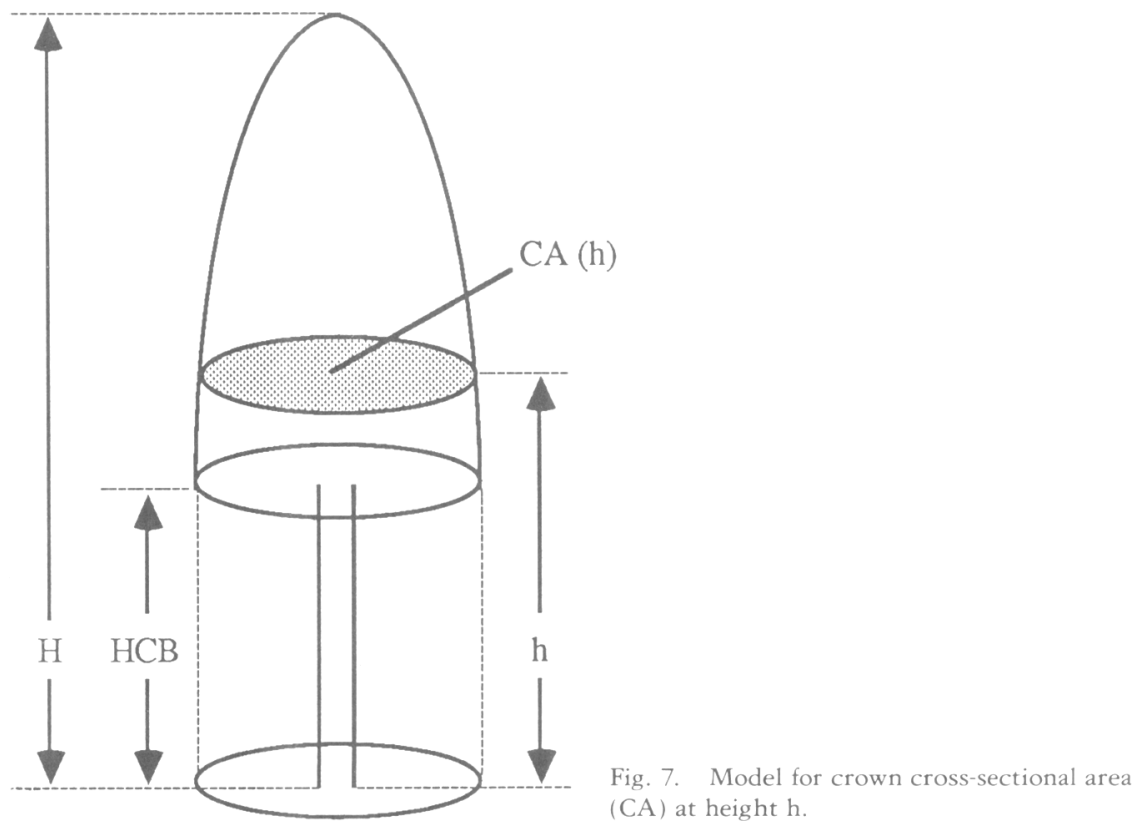


TABLE 3. COEFFICIENTS (AND STANDARD ERRORS) FOR

HEIGHT GROWTH POTENTIAL COMPONENTS, EQUATIONS [3] AND [4], AND THE COMPETITION COMPONENT, EQUATION [7]

\begin{tabular}{|c|c|c|c|c|c|c|}
\hline Coefficient & PP & SP & DF & WF & RF & IC \\
\hline \multicolumn{7}{|c|}{$\begin{array}{c}\text { POTENTIAL } \\
\mathrm{S}^{\prime}=\mathrm{S}+\partial \text { and } \mathrm{P}_{\mathrm{H}^{\prime}}=\mathrm{P}_{\mathrm{H}} \mathrm{d}_{1} /\left[1+\exp \left(4-\mathrm{d}_{2} \mathrm{LCR}\right)\right]\end{array}$} \\
\hline$\partial$ & $\begin{array}{l}17.60 \\
(4.51)\end{array}$ & $\begin{array}{l}14.34 \\
(4.77)\end{array}$ & $0.0^{*}$ & $0.0^{*}$ & $0.0^{*}$ & $0.0^{*}$ \\
\hline $\mathrm{d}_{1}$ & $1.00 *$ & $1.00 *$ & $1.00 *$ & $\begin{array}{l}1.00 * \\
(0.0453)\end{array}$ & $\begin{array}{r}0.7473^{\dagger} \\
(0.0345)\end{array}$ & $0.7096^{\dagger}$ \\
\hline $\mathrm{d}_{2}$ & $20.0^{*}$ & $20.0^{*}$ & $20.0^{*}$ & $20.0^{*}$ & $20.0^{*}$ & $20.0^{*}$ \\
\hline \multicolumn{7}{|c|}{$\begin{array}{c}\text { COMPETITION } \\
\mathrm{C}_{\mathrm{H}}=\exp \left(\mathrm{d}_{3} \mathrm{CC}_{66^{\mathrm{d}}}{ }^{\mathrm{P}} \mathrm{PBA}^{\mathrm{d} 5}\right)\end{array}$} \\
\hline$d_{3}$ & $\begin{array}{r}-1.4347 \\
(0.1790)\end{array}$ & $\begin{array}{r}-1.1322 \\
(0.1422)\end{array}$ & $\begin{array}{c}-0.6301 \\
(0.0555)\end{array}$ & $\begin{array}{l}-0.9010 \\
(0.1225)\end{array}$ & $-0.9010^{*}$ & $-0.9010^{*}$ \\
\hline $\mathrm{d}_{4}$ & $\begin{array}{c}0.7387 \\
(0.1515)\end{array}$ & $\begin{array}{c}0.8428 \\
(0.1969)\end{array}$ & $\begin{array}{l}1.0 * \\
(0.2454)\end{array}$ & 1.6555 & $1.6555^{*}$ & $1.6555 *$ \\
\hline$d_{5}$ & $\begin{array}{c}0.4483 \\
(0.1183)\end{array}$ & $0.0^{*}$ & $0.0^{*}$ & $0.0^{*}$ & $0.0^{*}$ & $0.0^{*}$ \\
\hline $\begin{array}{l}\text { Std. error }{ }^{S} \\
\text { (feet) }\end{array}$ & 1.54 & 1.19 & 1.59 & 2.06 & 1.20 & 1.48 \\
\hline $\mathrm{n}$ & 151 & 47 & 145 & 279 & 37 & 71 \\
\hline
\end{tabular}

*Coefficient held constant for regression.

${ }^{\dagger}$ Proportional adjustment added to the WF estimates to get estimates for red fir and incense cedar.

${ }^{\text {s }}$ Square root of mean square error (MSE).

single species. (Note that PBA is used only for ponderosa pine and is zero for other species and that $\mathrm{d}_{2}$ is fixed at 20 for all species.) Other coefficients were held constant for regression; this was due to insufficient data to fit all the coefficients to some species. For example, since red fir and incense cedar samples were small, only a scaling coefficient $\left(d_{1}\right)$ was fit; these two species use the competition coefficients fit for white fir. This procedure produced more stable results than fitting all coefficients to insufficient data. Also, site index for incense cedar was set to 70 because no incense cedar site measurements were taken for the stem analysis data set. Statistics for the height growth estimated from stem analysis data are given in appendix A.

The residual plots for ponderosa pine, Douglas-fir, and white fir showed that most of the errors are within 3 feet, with standard errors (square root of the mean square error, MSE) ranging from 1.2 to 2.0 feet. There is a distinct skewness to the residuals, especially for white fir. However, the residuals showed no overall bias with respect to predicted height growth or with respect to any of the predictors.

Thus, as judged against the stem analysis data used for estimation, the equations appear to fit well. For height growth this may be the best data set to use for verification - at least as far as the quality of the measurements is concerned. The difficulties and unreliable nature of other sources of height growth data suggest that it may be some time before a meaningful independent verification of a height growth model is possible. 


\section{Diameter Growth Coefficients}

Attempts at a simultaneous solution of all coefficients confounded the potential and competition effects. Therefore this approach was abandoned. Instead, an iterative process was used to obtain coefficients of equations [6] and [8]. First, a subset of the data was used to make an initial estimate of the coefficients for the potential component using trees growing under little or no competition. This subset, 5 to 10 percent of the total, was selected from the largest 33 percent of the trees in each stand (by basal area) provided that the trees had live crown ratios greater than 0.5 . It was assumed that these trees were not under significant competition, and the competition component was fixed at 1.0. Second, the coefficients $\mathrm{d}_{2}, \mathrm{~d}_{3}$, and $\mathrm{d}_{4}$ were estimated using all trees, with the potential components computed using the coefficients from the previous step. Finally, the coefficients $c_{0}, c_{1}, c_{2}$, and $c_{3}$ were re-estimated using all trees, with the other components computed using the coefficients from the second step. This iterative technique allows for more stable coefficient estimates with lower intra-component correlations.

As an independent check, the diameter growth coefficients estimated using the first subset of the permanent plot data were used to produce residuals for each species in both the second subset of the permanent plot data and the felled and nonfelled trees in the stem analysis data. These residuals were plotted against the independent variables for visual analysis of any linear or nonlinear trends. For both data sets, there were no apparent trends to these residual plots for any species except in the case of sugar pine and red fir. For these two species, the more limited sample range failed to reflect the entire permanent plot data set. Therefore, to provide more robust estimates for these two species, their coefficients were reestimated using the entire permanent plot data set. Statistics for the $\mathrm{DBH}^{2}$ growth estimates are shown in appendix $\mathrm{A}$ and a sample residual plot is shown in appendix $\mathrm{B}$. The residuals produced by these new coefficients produced no correlations with the independent predictors in the stem analysis data set.

The final coefficient estimates and standard errors for the diameter growth equations are given in table 4 . The standard errors (square roots of the mean square errors) vary from 8.3 to 13.4 (sq. in.). Expressing these standard errors in terms of DBH growth, they vary from 0.34 to 0.54 inches for 12 -inch trees, and 0.17 to 0.28 inches for 24-inch trees. The positive skewness noted in the height growth residuals is even more obvious in predicting $\mathrm{DBH}^{2}$ growth. Also, the residual variances increase with the size of the predictions as well as the size $(\mathrm{DBH})$ of the trees. However, the relative errors decrease. Small growth rates $\left(\triangle \mathrm{DBH}^{2}\right.$ less than 6 sq. in. ) appeared to be slightly underestimated. Attempts to reduce this bias either using weighted regression or fitting a transformed model only added to the bias of the small growth rates as well as decreasing the ability to predict the larger growth rates.

\section{DISCUSSION}

Accurate predictions of forest growth are essential for long run planning and evaluation of silvicultural regimes in the mixed conifer forests of northern California. Given a sufficient modelling base, individual tree simulation models can provide the longterm forecasts with sufficient detail to allow for economic and silvicultural analysis. To be useful, however, a forecasting system must be both logical and accurate. 
TABLE 4. COEFFICIENTS (AND STANDARD ERRORS) FOR DIAMETER GROWTH EQUATIONS [6] AND [8] AND CROWN ADJUSTMENT EQUATION [4]

\begin{tabular}{|c|c|c|c|c|c|c|}
\hline \multirow[b]{2}{*}{ Coefficient } & \multicolumn{6}{|c|}{ Species } \\
\hline & PP & $\mathbf{S} \mathbf{P}^{\dagger}$ & DF & WF & $\mathbf{R} \mathbf{F}^{\dagger}$ & IC \\
\hline \multicolumn{7}{|c|}{$\begin{array}{c}\text { POTENTIAL } \\
P_{D}=\left[c_{0} S^{c 1}+c_{2} D^{2}{ }^{c}\right]^{1 / c 3}-D^{2} \text { and } P_{D}=P_{D} /\left[1+\exp \left(4-d_{2} L C R\right)\right]\end{array}$} \\
\hline $\mathrm{c}_{0}$ & $\begin{array}{c}0.05166 \\
(0.00046)\end{array}$ & $\begin{array}{l}0.04973 \\
(0.00116)\end{array}$ & $\begin{array}{c}0.06732 \\
(0.00544)\end{array}$ & $\begin{array}{c}0.1938 \\
(0.0165)\end{array}$ & $\begin{array}{c}0.0991 \\
(0.0131)\end{array}$ & $\begin{array}{c}0.04831 \\
(0.00029)\end{array}$ \\
\hline$c_{1}$ & $0.03^{*}$ & $\begin{array}{c}-0.08063 \\
(0.03730)\end{array}$ & $\begin{array}{c}0.07856 \\
(0.01746)\end{array}$ & $\begin{array}{c}0.2123 \\
(0.0178)\end{array}$ & $\begin{array}{l}0.1073 \\
(0.0282)\end{array}$ & $0.03^{*}$ \\
\hline$c_{2}$ & $0.95 *$ & $0.95 *$ & $0.95^{*}$ & $0.95^{*}$ & $0.95^{*}$ & $0.95^{*}$ \\
\hline$c_{3}$ & $\begin{array}{c}0.02027 \\
(0.00111)\end{array}$ & $\begin{array}{r}-0.04024 \\
(0.01776)\end{array}$ & $\begin{array}{c}0.07793 \\
(0.01640)\end{array}$ & $\begin{array}{c}0.2799 \\
(0.0102)\end{array}$ & $\begin{array}{c}0.1398 \\
(0.0247)\end{array}$ & $\begin{array}{c}0.01027 \\
(0.00067)\end{array}$ \\
\hline$d_{2}$ & $\begin{array}{l}14.3255 \\
(0.3471)\end{array}$ & $\begin{array}{l}14.0764 \\
(0.4309)\end{array}$ & $\begin{array}{l}13.8772 \\
(0.4467)\end{array}$ & $\begin{array}{l}14.3776 \\
(0.3056)\end{array}$ & $\begin{array}{l}13.4858 \\
(0.5623)\end{array}$ & $\begin{array}{l}7.7401 \\
(0.3537)\end{array}$ \\
\hline \multicolumn{7}{|c|}{$\begin{array}{c}\text { COMPETITION } \\
\mathrm{C}_{\mathrm{D}}=\left[\exp \left(\mathrm{d}_{3} \operatorname{cc}_{66} \mathrm{~d}_{4}\right)\right]\end{array}$} \\
\hline$d_{3}$ & $\begin{array}{l}-1.3870 \\
(0.1595)\end{array}$ & $\begin{array}{l}-0.3321 \\
(0.0740)\end{array}$ & $\begin{array}{l}-0.5770 \\
(0.0604)\end{array}$ & $\begin{array}{c}-1.3907 \\
(0.0587)\end{array}$ & $\begin{array}{l}-1.9036 \\
(0.5038)\end{array}$ & $\begin{array}{l}-0.6093 \\
(0.0834)\end{array}$ \\
\hline $\mathrm{d}_{4}$ & $\begin{array}{l}1.4545 \\
(0.1254)\end{array}$ & $\begin{array}{l}0.6500 \\
(0.1761)\end{array}$ & $\begin{array}{c}0.7961 \\
(0.1055)\end{array}$ & $\begin{array}{c}1.0394 \\
(0.0455)\end{array}$ & $\begin{array}{c}2.3983 \\
(0.4185)\end{array}$ & $\begin{array}{c}0.4112 \\
(0.1579)\end{array}$ \\
\hline $\begin{array}{l}\text { Std. errors } \\
\text { (sq. in) }\end{array}$ & 8.81 & 12.63 & 9.29 & 9.51 & 11.88 & 8.31 \\
\hline $\mathrm{n}$ & 2064 & 905 & 1465 & 3123 & 579 & 1138 \\
\hline
\end{tabular}

*Coefficient held constant for regression.

${ }^{\dagger}$ Full permanent plot set was used in regression for SP and IC. For the other species half of the data, selected at random, was used.

${ }^{5}$ Square root of mean square error (MSE).

The growth models presented above were constructed to perform logically when extrapolating to new conditions. This was accomplished using a paradigm for growth that separates growth into two components, potential and competition. In this formulation, growth predictions are bounded to be less than or equal to that observed for dominant open growing trees. This structure helps ensure that predictions never become unrealistically large with time. This bounding characteristic is not present in empirically derived models and is a major advantage of the approach employed.

The diameter growth models reported herein were validated with independent data held in reserve for testing. Over 9,000 trees were held in reserve to test the diameter growth model. It was shown that the $\mathrm{DBH}$ model was accurate and had relatively low standard errors of prediction over the range of sizes observed (6-36 in. DBH).

The models and coefficients presented above have been incorporated into the mixed conifer projection system CACTOS (Wensel, Daugherty, and Meerschaert 1986). Experience from corporate, University and agency users has provided additional information as to the utility and accuracy of the models. Under some localized conditions calibration of the models may be warranted, but generally the base of users have found 
that the growth models in CACTOS predict values that are in concert with their inventory and research plot values. As more data become available, and more tests are conducted for validating these models, estimates can be revised by the calibration routines embedded in CACTOS. If indicated, major changes may require revisions of the model or changes in the values of the coefficients.

\section{APPENDICES}

APPENDIX A.1 SUMMARY STATISTICS FOR STEM ANALYSIS TREE DATA USED IN HEIGHT MODELLING

\begin{tabular}{lrrrr}
\hline \hline Ponderosa pine & & & & $\mathbf{n}=151$ \\
\hline Variable & Mean & Std. Dev. & Minimum & Maximum \\
\hline Height & 89.265 & 25.498 & 22.000 & 143.000 \\
Crown Ratio & 0.493 & 0.133 & 0.179 & 0.811 \\
CC 66 & 0.407 & 0.154 & 0.129 & 1.104 \\
SITE & 91.252 & 17.434 & 57.000 & 123.000 \\
HGR5 & 5.083 & 2.066 & 1.500 & 11.500 \\
POTENTIAL & 9.559 & 2.351 & 5.242 & 14.816 \\
ADJUSTMENT & 0.967 & 0.085 & 0.397 & 1.000 \\
COMPETITION & 0.556 & 0.105 & 0.326 & 0.878 \\
PREDICTED & 5.062 & 1.522 & 2.067 & 10.627 \\
\hline
\end{tabular}

\begin{tabular}{lrrrr}
\hline \hline Sugar pine & & & & $\mathbf{n}=\mathbf{4 7}$ \\
\hline Variable & Mean & Std. Dev. & Minimum & Maximum \\
\hline Height & 82.085 & 19.726 & 38.000 & 121.000 \\
Crown Ratio & 0.515 & 0.120 & 0.241 & 0.721 \\
CC 66 & 0.448 & 0.199 & 0.115 & 0.710 \\
SITE & 83.468 & 21.000 & 54.000 & 119.000 \\
HGR5 & 4.851 & 1.945 & 1.000 & 10.000 \\
POTENTIAL & 8.668 & 2.969 & 3.317 & 13.961 \\
ADJUSTMENT & 0.980 & 0.054 & 0.694 & 1.000 \\
COMPETITION & 0.478 & 0.115 & 0.352 & 0.833 \\
PREDICTED & 4.812 & 1.730 & 2.045 & 8.577 \\
\hline
\end{tabular}

\begin{tabular}{lrrrr}
\hline \hline Douglas-fir & \multicolumn{3}{c}{} & $\mathbf{n}=\mathbf{1 4 5}$ \\
\hline Variable & Mean & Std. Dev. & Minimum & Maximum \\
\hline Height & 79.014 & 25.373 & 30.000 & 141.000 \\
Crown Ratio & 0.563 & 0.132 & 0.175 & 0.935 \\
CC 66 & 0.495 & 0.223 & 0.086 & 1.094 \\
SITE & 76.779 & 13.447 & 55.000 & 116.000 \\
HGR5 & 4.497 & 1.731 & 1.000 & 9.000 \\
POTENTIAL & 6.134 & 1.940 & 2.058 & 11.038 \\
ADJUSTMENT & 0.988 & 0.057 & 0.378 & 0.948 \\
COMPETITION & 0.739 & 0.100 & 0.502 & 8.326 \\
PREDICTED & 4.422 & 1.457 & 1.414 & 1.000 \\
\hline
\end{tabular}


APPENDIX A.1. SUMMARY STATISTICS FOR STEM ANALYSIS TREE DATA USED IN HEIGHT GROWTH MODELLING (Continued)

\begin{tabular}{lrrrr}
\hline \hline White fir & \multicolumn{3}{c}{} & $\mathbf{n}=\mathbf{2 7 9}$ \\
\hline Variable & Mean & Std. Dev. & Minimum & Maximum \\
\hline Height & 68.792 & 24.380 & 13.000 & 122.000 \\
Crown Ratio & 0.549 & 0.167 & 0.163 & 0.929 \\
CC66 & 0.481 & 0.239 & 0.020 & 1.178 \\
SITE & 81.283 & 16.152 & 51.000 & 115.000 \\
HGR5 & 5.491 & 3.088 & 1.000 & 16.500 \\
POTENTIAL & 7.260 & 2.287 & 1.579 & 12.391 \\
ADJUSTMENT & 0.978 & 0.070 & 0.323 & 1.000 \\
COMPETITION & 0.757 & 0.158 & 0.307 & 0.999 \\
PREDICTED & 5.422 & 2.277 & 0.980 & 11.795 \\
\hline
\end{tabular}

\begin{tabular}{lrcrr}
\hline \hline Red fir & \multicolumn{3}{c}{} & $\mathbf{n}=37$ \\
\hline Variable & Mean & Std. Dev. & Minimum & Maximum \\
\hline Height & 78.703 & 12.673 & 40.000 & 97.000 \\
Crown Ratio & 0.525 & 0.145 & 0.274 & 0.862 \\
CC $_{66}$ & 0.485 & 0.166 & 0.267 & 0.965 \\
SITE & 69.567 & 4.592 & 61.000 & 73.000 \\
HGR5 & 2.892 & 1.214 & 0.500 & 5.000 \\
POTENTIAL & 5.244 & 1.379 & 2.584 & 8.043 \\
ADJUSTMENT & 0.735 & 0.026 & 0.609 & 0.747 \\
COMPETITION & 0.759 & 0.115 & 0.428 & 0.904 \\
PREDICTED & 2.844 & 0.567 & 1.718 & 3.595 \\
\hline
\end{tabular}

\begin{tabular}{lrrrr}
\hline \hline Incense cedar & \multicolumn{3}{c}{} & $\mathbf{n}=71$ \\
\hline Variable & Mean & Std. Dev. & Minimum & Maximum \\
\hline Height & 47.338 & 17.109 & 16.000 & 79.000 \\
Crown Ratio & 0.593 & 0.165 & 0.270 & 0.902 \\
CC 66 & 0.560 & 0.217 & 0.033 & 1.086 \\
SITE & 70.000 & 0.000 & 70.000 & 70.000 \\
HGR5 & 3.613 & 1.475 & 0.500 & 6.000 \\
POTENTIAL & 7.226 & 0.728 & 5.384 & 7.966 \\
ADJUSTMENT & 0.700 & 0.029 & 0.569 & 0.710 \\
COMPETITION & 0.705 & 0.145 & 0.356 & 0.997 \\
PREDICTED & 3.538 & 0.722 & 1.856 & 5.561 \\
\hline
\end{tabular}


APPENDIX A.2 SUMMARY STATISTICS FOR PERMANENT PLOT TREE DATA USED IN DBH ${ }^{2}$ MODELLING

\begin{tabular}{lrccr}
\hline \hline Ponderosa pine & & & & $\mathbf{n}=\mathbf{2 0 6 4}$ \\
\hline Variable & Mean & Std. Dev. & Minimum & Maximum \\
\hline DBH & 10.596 & 6.772 & 0.100 & 40.800 \\
Total Height & 53.351 & 32.659 & 0.000 & 184.000 \\
Crown Ratio & 0.470 & 0.172 & 0.020 & 0.950 \\
CC 66 & 0.434 & 0.219 & 0.022 & 1.590 \\
SITE & 69.734 & 16.971 & 38.000 & 140.000 \\
DGR5 & 12.939 & 15.138 & 0.172 & 116.480 \\
POTENTIAL & 20.268 & 16.070 & 0.010 & 96.110 \\
COMPETITION & 0.559 & 0.242 & 0.010 & 0.990 \\
PREDICTED & 12.636 & 12.681 & 0.008 & 78.520 \\
\hline
\end{tabular}

\begin{tabular}{lrrrr}
\hline \hline Sugar pine & & & & $\mathbf{n}=\mathbf{9 0 5}$ \\
\hline Variable & Mean & Std. Dev. & Minimum & Maximum \\
\hline DBH & 12.476 & 8.219 & 0.300 & 50.200 \\
Total Height & 57.705 & 34.783 & 0.000 & 171.000 \\
Crown Ratio & 0.488 & 0.164 & 0.040 & 0.950 \\
CC $_{66}$ & 0.480 & 0.250 & 0.017 & 1.330 \\
SITE & 74.866 & 14.963 & 43.000 & 115.000 \\
DGR5 & 23.029 & 26.457 & 0.172 & 163.200 \\
POTENTIAL & 32.203 & 30.084 & 0.052 & 202.120 \\
COMPETITION & 0.694 & 0.194 & 0.023 & 0.960 \\
PREDICTED & 22.872 & 23.518 & 0.047 & 165.760 \\
\hline
\end{tabular}

\begin{tabular}{lrrrr}
\hline \hline Douglas-fir & & & & $\mathbf{n}=\mathbf{1 4 6 5}$ \\
\hline Variable & Mean & Std. Dev. & Minimum & Maximum \\
\hline DBH & 9.470 & 6.020 & 0.100 & 40.000 \\
Total Height & 52.769 & 29.620 & 0.000 & 170.000 \\
Crown Ratio & 0.511 & 0.181 & 0.043 & 0.980 \\
CC 66 & 0.578 & 0.316 & 0.032 & 1.590 \\
SITE & 76.659 & 15.001 & 43.000 & 157.000 \\
DGR5 & 14.077 & 15.732 & 0.080 & 134.010 \\
POTENTIAL & 21.472 & 16.251 & 0.019 & 87.870 \\
COMPETITION & 0.600 & 0.201 & 0.020 & 0.960 \\
PREDICTED & 13.999 & 12.780 & 0.015 & 74.970 \\
\hline
\end{tabular}

\begin{tabular}{lrrrr}
\hline \hline White fir & \multicolumn{1}{c}{} & $\mathbf{n}=3123$ \\
\hline Variable & Mean & Std. Dev. & Minimum & Maximum \\
\hline DBH & 8.784 & 6.237 & 0.600 & 41.100 \\
Total Height & 43.206 & 29.737 & 0.000 & 168.000 \\
Crown Ratio & 0.503 & 0.201 & 0.032 & 0.980 \\
CC 66 & 0.585 & 0.303 & 0.015 & 1.620 \\
SITE & 72.425 & 16.558 & 35.000 & 124.000 \\
DGR5 & 13.105 & 16.595 & 0.172 & 133.350 \\
POTENTIAL & 27.428 & 18.876 & 1.237 & 94.420 \\
COMPETITION & 0.414 & 0.221 & 0.006 & 0.980 \\
PREDICTED & 13.105 & 13.569 & 0.041 & 79.420 \\
\hline
\end{tabular}


APPENDIX A.2. SUMMARY STATISTICS FOR PERMANENT PLOT TREE DATA USED IN DBH ${ }^{2}$ GROWTH MODELLING (Continued)

\begin{tabular}{lrccr}
\hline \hline Red fir & & & & $\mathbf{n}=\mathbf{5 7 9}$ \\
\hline Variable & Mean & Std. Dev. & Minimum & Maximum \\
\hline DBH & 11.634 & 7.881 & 0.600 & 50.800 \\
Total Height & 53.737 & 34.716 & 5.000 & 154.000 \\
Crown Ratio & 0.471 & 0.188 & 0.033 & 0.940 \\
CC $_{66}$ & 0.495 & 0.315 & 0.027 & 1.380 \\
SITE & 64.803 & 12.777 & 31.000 & 104.000 \\
DGR5 & 18.272 & 21.306 & 0.172 & 126.600 \\
POTENTIAL & 28.226 & 19.675 & 0.463 & 83.790 \\
COMPETITION & 0.551 & 0.322 & 0.004 & 1.000 \\
PREDICTED & 18.113 & 17.856 & 0.008 & 71.410 \\
\hline
\end{tabular}

\begin{tabular}{lrrrr}
\hline \hline Incense cedar & & & & $\mathbf{n}=1138$ \\
\hline Variable & Mean & Std. Dev. & Minimum & Maximum \\
\hline DBH & 8.628 & 6.550 & 0.500 & 66.600 \\
Total Height & 31.933 & 22.432 & 4.000 & 182.000 \\
Crown Ratio & 0.472 & 0.205 & 0.000 & 0.980 \\
CC $_{66}$ & 0.581 & 0.269 & 0.041 & 1.560 \\
SITE & 74.504 & 15.801 & 29.000 & 124.000 \\
DGR5 & 8.176 & 11.807 & 0.170 & 134.200 \\
POTENTIAL & 23.256 & 25.266 & 0.186 & 224.820 \\
COMPETITION & 0.278 & 0.188 & 0.011 & 0.820 \\
PREDICTED & 6.927 & 9.673 & 0.002 & 114.500 \\
\hline
\end{tabular}

APPENDIX B. EXAMPLE OF RESIDUAL PATTERNS:

ACTUAL - PREDICTED DBH ${ }^{2}$ GROWTH AGAINST PREDICTED DBH ${ }^{2}$ GROWTH FOR WHITE FIR

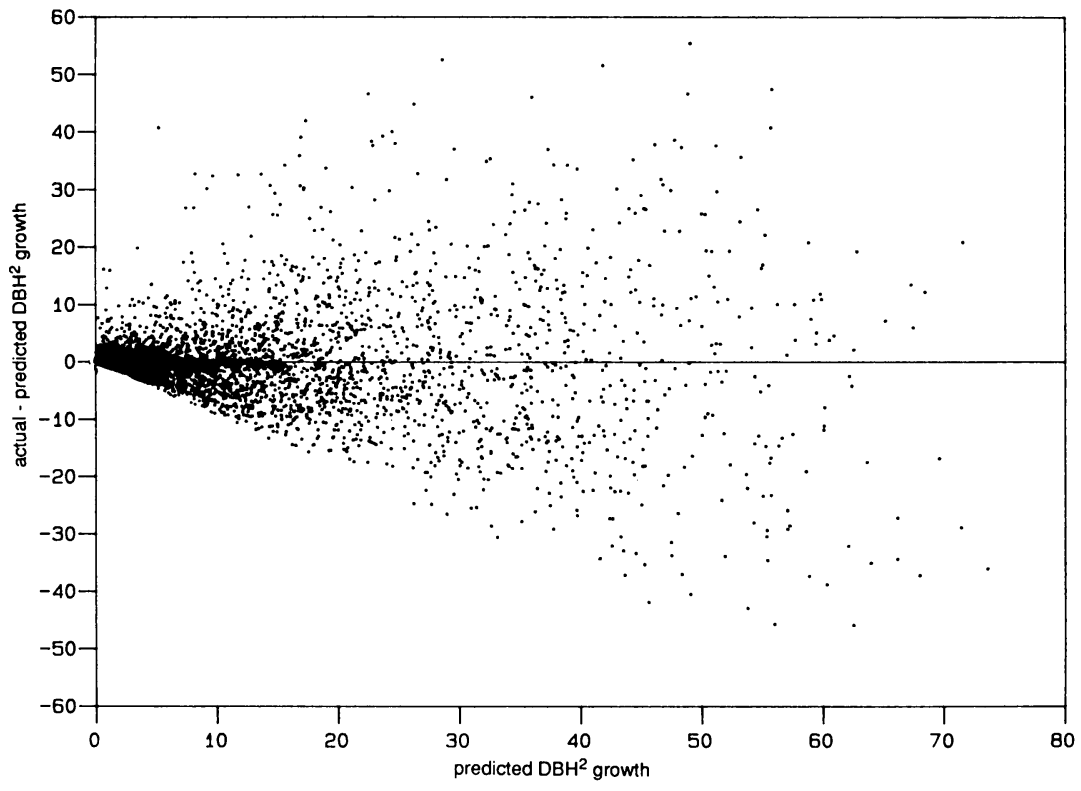




\section{LITERATURE CITED}

BAULE, B.

1917. Zu Mitscherlichs gesetz der physiologischen beziehungen. Landw. Jahrb. 51(3):363-85.

BELCHER, DAVID W., MARGARET R. HOLDAWAY and GARY J. BRAND

1982. A description of STEMS, the stand and tree evaluation and modeling system. USDA-FS Gen. Tech. Rept. NC-79. 18 p.

BIGING, GREG S.

1984. Taper equations for second-growth mixed conifers of northern California. For. Sci. 30(4): 1103-17.

1985. Improved estimates of site index curves using a varying parameter model. For. Sci. 31(1): 248-59.

BIGING, GREG S., and LEE C. WENSEL

1984. A photographic technique for use with stem analysis. For. Sci. 30(3):715-29.

1985. Site index equations for young-growth mixed conifers of northern California. N. Calif. Forest Yield Coop. Res. Note No. 8, Dept. of For. and Res. Mgt., Univ. Calif., Berkeley.

1987. The geometry of crowns in mixed-conifer forests of the northern Sierra Nevada. Unpublished.

DANIELS, RICHARD F., HAROLD E. BURKHART, and TERRY R. CLASON

1987. A comparison of competition measures for predicting growth of loblolly pine trees. Can. J. For. Res. 16(6):1230-37.

EK, ALAN R., and ROBERT A. MONSERUD

1974. FOREST: A computer model for simulating the growth and reproduction of mixed species forest stands. Research Report A2635. School of Natural Resources, Univ. of Wisc. 13 p. plus appendices.

FERGUSON, DENISE E., and DAVID L. ADAMS

1980. Response of advance Grand Fir regeneration to overstory removal in northern Idaho. For. Sci. 26(4):537-45.

HAHN, JEROLD T., and ROLFE A. LEARY

1979. Potential diameter growth functions. In: A generalized forest growth projection system applied to the Lake States region. USDA-FS Gen. Tech. Rep. NC-49. 22-26 p.

HELMS, JOHN A. and RICHARD B. STANDIFORD

1985. Predicting release of advance reproduction of mixed conifer species in California following overstory removal. For. Sci. 31(1):3-15.

KRUMLAND, BRUCE E.

1982. A tree-based forest yield projection system for the north coast region of California. Ph.D. dissertation. Univ. of California, Berkeley, $188 \mathrm{p}$.

KRUMLAND, BRUCE E., and LEE C. WENSEL

1981. A tree increment model system for north coastal California, design and implementation. Coop. Redwood Yield Res. Proj. Res. Note No. 15, Univ. Calif. Berkeley.

1982. CRYPTOS - User's Guide, Cooperative Redwood Yield Project Timber Output Simulator, version 4.0. Coop. Redwood Yield Res. Proj. Res. Note No. 20, Univ. Calif., Berkeley.

LEARY, ROLFE A., and MARGARET R. HOLDAWAY

1979. Modifier function. In: A generalized forest growth projection system applied to the Lake States region. USDA-FS Gen. Tech. Rept. NC-49. 96 p.

LORIMER, GREG G.

1983. Tests of age-independent competition indices for individual trees in natural hardwood stands. For. Ecol. and Mgt. 6:343-60.

MARTIN, GEORGE L., and ALAN R. EK

1984. A comparison of competition measures and growth models for predicting plantation red pine diameter and height growth. For. Sci. 30(3):731-43.

MONSERUD, ROBERT A.

1975. Methodology for simulating Wisconsin northern hardwood stand dynamics. Ph.D. thesis. Univ. Wisc.-Madison (Univ. Microfilms 76-2496). 156 p.

OLIVER, WILLIAM W.

1986. Growth of California red fir advance regeneration after overstory removal and thinning. USDA-FS Res. Note PSW-180.6 p.

OPIE, JACK E.

1968. Predictability of individual tree growth using various definitions of competing basal area. For. Sci. 14:314-23.

SEIDEL, K. W.

1980. Diameter and height growth of suppressed grand fir saplings after overstory removal. USDAFS Res. Paper PNW-275. 9 p.

STAGE, ALBERT R.

1973. Prognosis model for stand development. USDA-FS Res. Note. INT-137, 32 p.

1975. Prediction of height increment for models of forest growth. USDA-FS Res. Note INT-164. 20 p. 
VAN DEUSEN, PAUL C. and GREG S. BIGING

1984. Crown volume and dimensional models for mixed conifers of the Sierra Nevada. N. Calif. Forest Yield Coop. Res. Note No. 8, Dept. of For. and Res. Mgt., Univ. of Calif., Berkeley.

WENSEL, LEE C., PETER J. DAUGHERTY, and WALTER J. MEERSCHAERT.

1986. CACTOS user's guide: The California conifer timber output simulator. Div. of Ag. Nat. Res., Univ. of Calif., Oakland, Bulletin 1920.

WYKOFF, WILLIAM R.

1985. Supplement to the user's guide for the stand prognosis model-version 5.0. USDA-FS Gen. Tech. Report INT-208. 36 p.

WYKOFF, WILLIAM R., N. L. CROOKSTON, and ALBERT R. STAGE

1982. User's guide to the stand prognosis model. USDA-FS Res. Note INT-133. 112 p.

\section{ACKNOWLEDGMENTS}

The authors thank James Koehler for his important contributions to the development of early versions of the models presented here, the reviewers for their helpful suggestions, and the members of the Northern California Forest Yield Cooperative for their support.

The University of California, in compliance with the Civil Rights Act of 1964, Title IX of the Educational Amendments of 1972, and the Rehabilitation Act of 1973, does not discriminate on the basis of race, creed, religion, color, national origin, sex, or mental or physical handicap in any of its programs or activities, or with respect to any of its employment policies, practices, or procedures. The University of California does not discriminate on the basis of age, ancestry, sexual orientation, marital status, citizenship, medical condition (as defined in section 12926 of the California Government Code), nor because individuals are disabled or Vietnam era veterans. Inquiries regarding this policy may be directed to the Personnel Studies and Affirmative Action Manager, Division of Agriculture and Natural Resources, 2120 University Avenue, University of California, Berkeley, California 94720, (415) 644-4270. 